DAvis, G. H. G. (1955). J. gen. Microbiol. 13, 481-493

\title{
The Glassification of Lactobacilli from the Human Mouth
}

\author{
By G. H. G. DAVIS \\ Department of Bacteriology, University of Birmingham
}

SUMMARY : A scheme of classification for Lactobacillus strains from diverse sources is proposed, based upon the results obtained with $\mathbf{4 7 3}$ strains, mainly of human oral origin, using a selected range of morphological and physiological taxonomic criteria. Two subgeneric groups, containing five stable and clearly demarcated specific types are recognized.

The lack of a satisfactory classification of the genus Lactobacillus is reflected in the number of recent systematic studies which have been published, and which have been reviewed, together with much of the earlier work, by Briggs \& Briggs (1954). Almost all the taxonomic techniques known to bacteriology have been employed, at various times, by the many workers in this field. Studies by Tilden \& Svec (1952), Rogosa, Wiseman, Mitchell, Disraely \& Beaman (1953), Grubb \& Krasse (1953), Briggs (1953), Wheater (1955 $a, b)$ and Sharpe (1955) have clarified the status of some named species, but, as will become evident, it is not considered that any of these, or indeed the present work, provides the final word upon the subject.

The object of this investigation was to examine and select a combination of simple and easily applied physiological tests, in addition to the morphological criteria already described (Davis, Bisset \& Hale, 1955), whereby the oral lactobacilli might readily be identified and classified within a system applicable to the entire genus. The eventual purpose is to clarify the role of these bacteria in dental caries.

\section{METHODS}

\section{Isolation and purification}

All the strains examined were freshly isolated except 28 obtained from the National Collection of Industrial Bacteria, (NCIB), Teddington, and 27 from the National Institute for Research in Dairying, (NIRD), Shinfield, by courtesy of Dr M. E. Sharpe. Their origins, and in the case of the type cultures, their numbers and original designations, are shown in Tables 2-4.

The complex tomato juice (TJ) medium previously described (Davis $e t$ al. 1955) was used throughout the study for routine cultivation of Lactobacillus. It is based upon those of Kulp (1927), Rogosa, Mitchell \& Wiseman (1951) and Briggs (1953), and gave satisfactory results both in liquid form and when solidified by the addition of $2 \cdot 5 \%$ agar.

Primary cultures were made in broth in bijou bottles, and the growth was plated out at intervals over a period of 4-6 days of incubation at $37^{\circ}$. Colonies were picked from $48 \mathrm{hr}$. cultures on the solid medium, and the strains were purified by alternate growth in broth for 24-96 hr., from which colonies were 
again picked. The process was repeated until uniformity of appearance in agar surface cultures indicated purity.

Although good growth was obtainable in $24 \mathrm{hr}$. in $\mathbf{T J}$ broth, prolonged incubation, for 4 to 6 days, greatly assisted the isolation of lactobacilli, because they survived the conditions of falling $\mathrm{pH}$ value much more easily than did most of the other oral bacteria, e.g. streptococci.

Table 1. Comparison of overall group characteristics

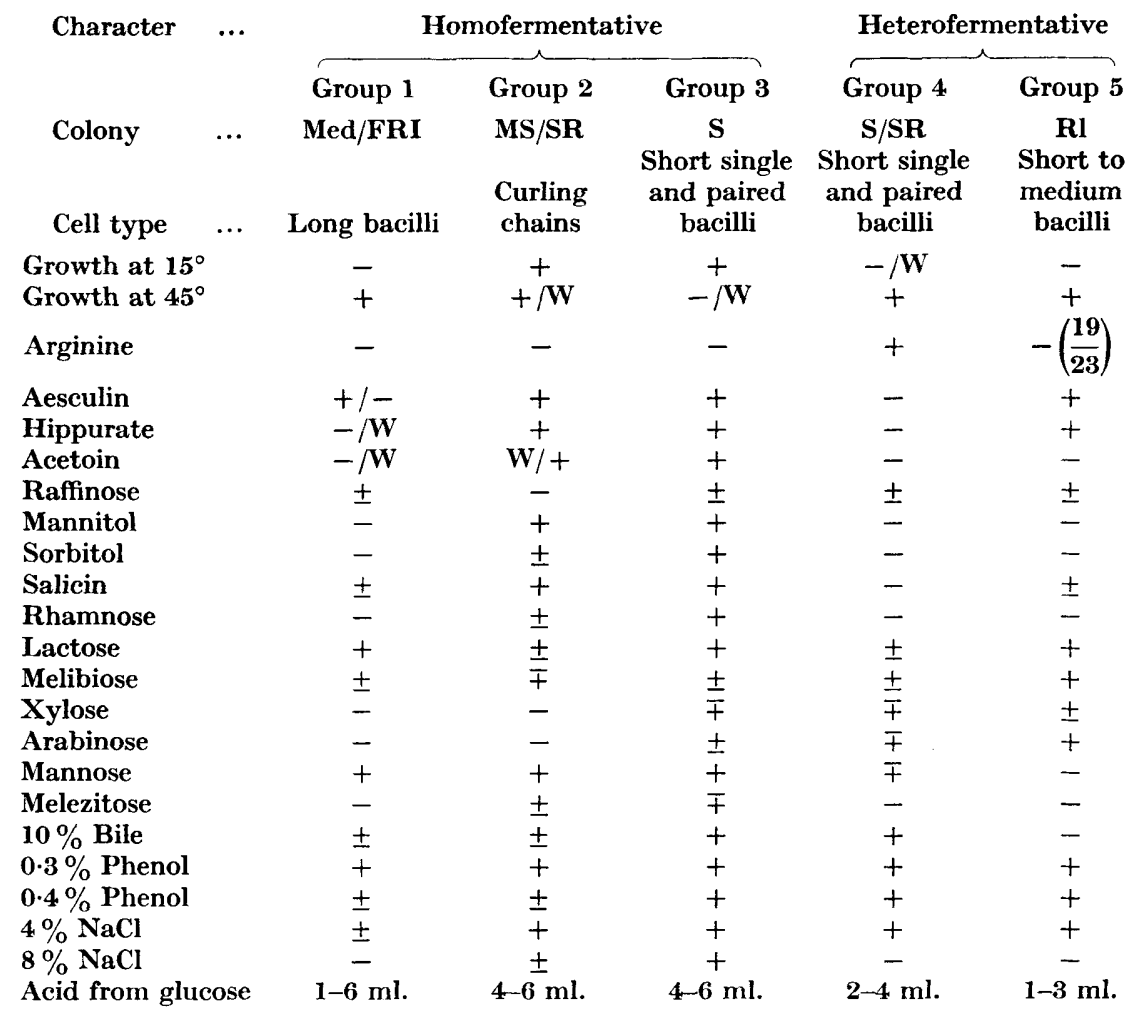

Colonies: $\mathbf{M e d}=$ 'Medusa-head'; $\mathbf{F}=$ flat $; \mathbf{R}=$ rough; $\mathbf{S}=$ smooth; $\mathbf{I}=$ irregular; $\mathbf{M}=$ 'Mucoid'.

$+=$ normally positive; $-=$ normally negative; $\pm=$ over $50 \%$ of strains positive; $\mp=$ less than $50 \%$ of strains positive; $W=$ weak reaction.

When TJ medium was used, no special techniques for the production of anaerobic or microaerophilic conditions were necessary. All strains of lactobacilli encountered grew well at $37^{\circ}$ under aerobic conditions. When not required for immediate examination, strains were maintained in cooked meat medium (Mackie \& McCartney, 1950, p. 185), as recommended by Sullivan (1939).

\section{Preliminary identification}

The strains to be examined were first identified as members of the genus Lactobacillus. Gram-staining, general morphology and motility were examined in $24 \mathrm{hr}$. TJ broth cultures. 
Catalase production was tested by pipetting one drop of $3 \%(v / v)$ hydrogen peroxide over $48 \mathrm{hr}$. discrete surface colonies, and examining for effervescence under the wide-field microscope. Candidas and most staphylococci were readily detected by this means.

Table 2. Classification of NCIB strains

\begin{tabular}{ccl}
$\begin{array}{c}\text { Present } \\
\text { grouping }\end{array}$ & NCIB no. & \multicolumn{1}{c}{ Deposited as } \\
1 & 8118 & L. leichmanii \\
& 8170 & L. lactis \\
& 4504 & L. acidophilus \\
2 & 1723 & L. acidophilus \\
& 1407 & L. acidophilus-odontolyticus \\
& 1406 & L. acidophilus-odontolyticus \\
& 8103 & L. helveticus \\
& 7473 & L. delbrueckii \\
& 8019 & L. casei \\
& 8010 & L. casei \\
& 6375 & L. helveticus \\
& 8125 & L. delbrueckii \\
& 6461 & L. plantarum \\
& 4504 a & L. acidophilus \\
& 8531 & L. plantarum \\
& 8026 & L. plantarum \\
& 4505 & L. acidophilus \\
& 8028 & L. fermenti \\
& 6991 & L. fermenti \\
Not lactobacilli & $\mathbf{8 1 3 0}$ & L. delbrueckii \\
& $\mathbf{8 1 2 1}$ & L. enzymothermophilus \\
& &
\end{tabular}

Nitrate reduction was tested in the following medium: Oxoid peptone, $0.5 \%(\mathrm{w} / \mathrm{v})$; Difco yeast extract, $0.3 \%(\mathrm{w} / \mathrm{v})$; glucose, $0.5 \%(\mathrm{w} / \mathrm{v})$; agar, $0.1 \%(\mathrm{w} / \mathrm{v})$; potassium nitrate $\left(\mathrm{KNO}_{3}\right), 0.2 \%(\mathrm{w} / \mathrm{v})$; Salts $\mathbf{A}, 0.5 \%(\mathrm{v} / \mathrm{v})$; and Salts $\mathrm{B}, 0.5 \%(\mathrm{v} / \mathrm{v})$. The $\mathrm{pH}$ was adjusted to 6.8 and the medium dispensed into $5 \times \frac{1}{2}$ in. tubes, each half-filled, and autoclaved at $15 \mathrm{lb}$. for $15 \mathrm{~min}$. The inoculum consisted of 2 or 3 drops of $24 \mathrm{hr}$. TJ broth culture delivered from a capillary pipette. The tests were incubated for 6 days at $37^{\circ}$, and to each test was added one drop of dilute iodine solution and $1 \mathrm{ml}$. of each of the Griess-Ilosvay reagents (Topley \& Wilson, 1946, p. 368). The tests were allowed to stand at room temperature for $30 \mathrm{~min}$. and the results noted; false negative reactions were checked by the addition of powdered zine and further observations of colour change. The presence of adequate growth was always noted before the test was made.

Polysaccharide production when grown on $5 \%$ sucrose-TJ agar was examined by observation of colonies after 4 days at $37^{\circ}$. The sucrose solution employed was sterilized by Seitz filtration. 
Strains accepted as members of the genus Lactobacillus in this study were Gram-positive rods, non-sporing, non-motile; they did not produce catalase, reduce nitrate or produce copious polysaccharide material from sucrose.

Table 3. Classification of NIRD strains (homofermentative only)

\begin{tabular}{|c|c|c|c|c|}
\hline $\begin{array}{l}\text { Present } \\
\text { grouping }\end{array}$ & NIRD no. & Original designation & Wheater, 1955 & Sharpe, 1955 \\
\hline \multirow[t]{9}{*}{1} & $\begin{array}{l}\text { B2 } \\
\text { B14 } \\
\text { B12 } \\
\text { AH4 }\end{array}$ & $\begin{array}{l}\text { L. bulgaricus } \\
\text { L. bulgaricus } \\
\text { L. bulgaricus } \\
\text { N.C. }\end{array}$ & $\begin{array}{l}\text { L. bulgaricus } \\
\text { L. bulgaricus } \\
\text { L. bulgaricus } \\
\text { L. bulgaricus- } \\
\text { acidophilus }\end{array}$ & $\begin{array}{l}\text { L. bulgaricus } \\
\text { L. bulgaricus } \\
\text { L. bulgaricus } \\
\text { N.C. }\end{array}$ \\
\hline & L15 & L. lactis & N.T. & L. lactis \\
\hline & L1 & L. lactis & N.T. & L. lactis \\
\hline & L6 & L. lactis & N.T. & L. lactis \\
\hline & A12 & L. acidophilus & L. acidophilus & N.C. \\
\hline & A4 & L. acidophilus & L. acidophilus & N.C. \\
\hline & AI & L. acidophilus & L. acidophilus & N.C. \\
\hline & A18 & L. acidophilus & L. acidophilus & N.C. \\
\hline & L3 & L. lactis & N.T. & L. lactis \\
\hline \multirow[t]{8}{*}{2} & C5 & L. casei & L. casei & $\begin{array}{l}\text { L. casei- } \\
\quad \text { helveticus }\end{array}$ \\
\hline & C6 & L. casei & L. casei & L. casei \\
\hline & C9 & L. casei & L. casei & L. casei \\
\hline & or & N.C. & L. casei & L. casei \\
\hline & C2 & L. casei & L. casei & $\begin{array}{l}\text { L. casei- } \\
\quad \text { helveticus }\end{array}$ \\
\hline & $\mathrm{Cl} 7$ & L. casei & L. helveticus & L. helveticus \\
\hline & H2 & L. helveticus & L. helveticus & L. helveticus \\
\hline & H5 & L. helveticus & L. helveticus & L. helveticus \\
\hline \multirow[t]{4}{*}{$\mathbf{3}$} & P5 & L. plantarum & L. plantarum & L. plantarum \\
\hline & P4 & L. plantarum & L. plantarum & L. plantarum \\
\hline & AR1 & L. arabinosus & L. plantarum & L. plantarum \\
\hline & AR5 & L. arabinosus & L. plantarum & L. plantarum \\
\hline
\end{tabular}

N.T. $=$ not tested; N.C. $=$ not classified.

\section{Physiological tests}

The following physiological tests were selected from the very large number recorded in the literature and modified by a process of trial and error; they were employed for the classification of Lactobacillus strains. All inoculations were made by sterile capillary pipette from active $24 \mathrm{hr}$. TJ broth cultures, after at least two subcultures in that medium at $24 \mathrm{hr}$. intervals. Unless otherwise indicated, the incubation temperature for all tests was $37^{\circ}$. The peptone used in all media was the Oxoid product and the yeast extract, Difco. The salts A and $\mathbf{B}$ are those employed in the TJ medium already described (Davis $e t$ al. 1955).

Gas production from glucose. Medium: peptone, $1 \%(\mathrm{w} / \mathrm{v})$; yeast extract, $0.5 \%(w / v)$; glucose, $3 \%(\mathrm{w} / \mathrm{v})$; Tween 80, 0.1 \% (v/v); Salts A, 0.5\% (v/v); Salts $\mathrm{B}, \mathbf{0 . 5} \%(\mathrm{v} / \mathrm{v}) ; \mathrm{pH} \mathbf{7 \cdot 2}$, with $0.2 \%(\mathrm{v} / \mathrm{v})$ of $1.5 \%$ aqueous solution of bromocresol-purple added. Dispensed into $5 \times \frac{1}{2}$ in. tubes containing inverted Durham tubes and steamed for $20 \mathrm{~min}$. on 3 consecutive days to sterilize. The 
casein digest fermentation test medium described below was also found to be effective as the basal medium for this test. After inoculation with 3 to 4 drops, the tests were sealed by a layer of $c .1 \mathrm{ml}$. of sterile liquid paraffin. They were incubated for 6 days and observed every $48 \mathrm{hr}$.

Ammonia production from arginine. Medium: peptone, 0.5\% (w/v); yeast extract, $0.3 \%(\mathrm{w} / \mathrm{v})$; glucose, $0.3 \%(\mathrm{w} / \mathrm{v})$; sodium acetate, $1 \%(\mathrm{w} / \mathrm{v})$; L-arginine hydrochloride, $0.3 \%(\mathrm{w} / \mathrm{v})$; Tween $\mathbf{8 0 , 0 . 1} \%(\mathrm{v} / \mathrm{v})$; Salts A, $0.5 \%$ $(\mathrm{v} / \mathrm{v})$; Salts $\mathrm{B}, 0.5 \%(\mathrm{v} / \mathrm{v}) ; \mathrm{pH} 7 \cdot 4$, dispensed in $4 \mathrm{ml}$. quantities in $\frac{1}{4} \mathrm{oz}$. (bijou) bottles and steamed 20 min. on 3 consecutive days to sterilize. Tests were inoculated with 1 to 2 drops, incubated for 10 days and tested by adding $1 \mathrm{ml}$. of Nessler's reagent to detect ammonia.

Table 4. Source, numerical distribution and classification of 473 strains of Lactobacillus

\begin{tabular}{|c|c|c|c|c|c|c|}
\hline \multirow[b]{2}{*}{ Source } & \multicolumn{5}{|c|}{ Lactobacillus groups } & \multirow{2}{*}{$\begin{array}{l}\text { Source } \\
\text { totals }\end{array}$} \\
\hline & $\mathbf{1}$ & 2 & $\mathbf{3}$ & 4 & 5 & \\
\hline Saliva & 2 & 33 & 1 & 75 & 2 & 113 \\
\hline Filled teeth & 5 & 16 & 1 & 5 & . & 27 \\
\hline Carious teeth & 19 & 41 & . & $\mathbf{5 5}$ & 8 & 123 \\
\hline Tooth surfaces & 7 & 58 & . & 16 & 9 & 90 \\
\hline Caries-free salivas & 5 & 32 & 3 & 10 & . & 50 \\
\hline Yoghurt & 3 & . & . & . & . & 3 \\
\hline Milk & . & 12 & . & . & . & 12 \\
\hline NIRD & 12 & 11 & 4 & . & . & 27 \\
\hline NCIB & 4 & 12 & 5 & 3 & 4 & 28 \\
\hline Group totals & 57 & 215 & 14 & 164 & 23 & 473 \\
\hline
\end{tabular}

Hydrolysis of sodium hippurate. Medium: peptone, $1 \%(\mathrm{w} / \mathrm{v})$; yeast extract, $0.5 \%(\mathrm{w} / \mathrm{v})$; glucose, $0.5 \%(\mathrm{w} / \mathrm{v})$; sodium hippurate, $1 \%(\mathrm{w} / \mathrm{v})$; sodium chloride, $0.5 \%(\mathrm{w} / \mathrm{v})$; Tween 80, 0.1\% (v/v); Salts A, 0.5\% (v/v); Salts B, $0.5 \%(\mathrm{v} / \mathrm{v}) ; \mathrm{pH} 6.8$, bottled in $c .5 \mathrm{ml}$. quantities in $\frac{1}{4} \mathrm{oz}$. bottles and sterilized by steaming for $20 \mathrm{~min}$. on 3 consecutive days.

Tests were inoculated with 1 to 2 drops, incubated for 10 days, and tested by removing two $1 \mathrm{ml}$. samples of clear supernatant culture fluid (centrifuged if necessary) to two clean $5 \times \frac{1}{2}$ in. tubes. To one $0.5 \mathrm{ml}$. ferric chloride reagent (12\% ferric chloride solution plus $2.5 \mathrm{ml}$. concentrated hydrochloric acid per litre) was added, and to the other $1 \mathrm{ml}$. of a $50 \%$ sulphuric acid solution. They were allowed to stand, and shaken occasionally for 30-60 min. A fine crystalline precipitate indicated a positive reaction. The role of both reagents is to detect free benzoic acid; weak positive hydrolysis however may only be detectable by the sulphuric acid test. If allowed to stand for $24 \mathrm{hr}$, large needle-like crystals of unknown composition appeared in some of the sulphuric acid tests but these did not indicate a true positive reaction.

Hydrolysis of aesculin. Medium: peptone, $1 \%(\mathrm{w} / \mathrm{v})$; yeast extract, $0.5 \%$ $(\mathrm{w} / \mathrm{v})$; sodium acetate, $1 \%(\mathrm{w} / \mathrm{v})$; aesculin, $0.5 \%(\mathrm{w} / \mathrm{v})$; ferric ammonium citrate, $0.05 \%(\mathrm{w} / \mathrm{v})$; Tween 80, $0.1 \%(\mathrm{v} / \mathrm{v})$; Salts A, 0.5\% (v/v); Salts B, $0.5 \%(\mathrm{v} / \mathrm{v})$; at $\mathrm{pH} 6.8$, dispensed in $4 \mathrm{ml}$. quantities into bijou bottles and 
autoclaved at $10 \mathrm{lb}$. for $20 \mathrm{~min}$. to sterilize. The tests were inoculated with 1 to 2 drops, incubated for 14 days and observed at $48 \mathrm{hr}$. intervals for loss of fluorescence and blackening of the culture, indicating hydrolysis.

Acetylmethylcarbinol (acetoin) production from glucose. Medium: peptone, $\mathbf{0 . 5} \%(\mathrm{w} / \mathrm{v})$; yeast extract, $\mathbf{0 . 3} \%(\mathrm{w} / \mathrm{v})$; sodium acetate, $0.5 \%(\mathrm{w} / \mathrm{v})$; glucose $2 \%(w / v)$; Tween 80, 0.1 \% (v/v); Salts A, 0.5\% (v/v); Salts B, 0.5\% (v/v); at pH $6 \cdot 8$, dispensed in $3 \mathrm{ml}$. quantities into bijou bottles and sterilized by steaming for 20 min. on 3 consecutive days.

Tests were inoculated with 1 to 2 drops, incubated for 10 days, and tested by transferring the culture to a clean test-tube, adding a few granules of creatine, $0.6 \mathrm{ml}$. of $5 \% \alpha$-naphthol solution in absolute ethanol and $0.2 \mathrm{ml}$. of $40 \%$ potassium hydroxide solution (Barritt, 1936). Positive reactions varied in the intensity of the red colour produced with these reagents.

Fermentation of selected carbohydrates. Medium: casein partial-hydrolysate (Peters \& Snell, 1954) was prepared as follows: $112 \mathrm{~g}$. of BDH light white soluble casein in $1600 \mathrm{ml}$. of N-sulphuric acid was autoclaved for $5 \mathrm{hr}$. at $15 \mathrm{lb}$. Approximately $180 \mathrm{~g}$. of barium hydroxide was mixed in thoroughly; the $\mathrm{pH}$ re-adjusted to $c .3 \cdot 0$ with $\mathrm{N}$-sulphuric acid; $56 \mathrm{~g}$. of activated charcoal were added and mixed well for $30 \mathrm{~min}$. The solution was filtered through paper pulp on a Buchner funnel.

A double-strength basal medium was then prepared by adding $56 \mathrm{~g}$. of peptone, $28 \mathrm{~g}$. of yeast extract, $5.6 \mathrm{ml}$. of Tween $80,28 \mathrm{ml}$. of Salts A and $28 \mathrm{ml}$. of Salts B to the casein hydrolysate solution and diluting to a final volume of $2800 \mathrm{ml}$. After steaming to dissolve the solids the $\mathrm{pH}$ was adjusted to $\mathbf{7 \cdot 0}$, the medium re-steamed for $20 \mathrm{~min}$. and clarified by filtration through paper pulp. This medium was autoclaved for $15 \mathrm{~min}$. at $15 \mathrm{lb}$. and stored in $250 \mathrm{ml}$. quantities. Fermentation tests were prepared by diluting $250 \mathrm{ml}$. of the double-strength medium to $450 \mathrm{ml}$., adjusting the $\mathrm{pH}$ to $7 \cdot 2$, adding $1 \mathrm{ml}$. of a $1.5 \%$ aqueous solution of bromocresol-purple, and in the case of heat tolerant carbohydrates, $50 \mathrm{ml}$. of $10 \%$ carbohydrate solution. The final medium was dispensed into bijou bottles and sterilized by steaming for $20 \mathrm{~min}$. on 3 consecutive days. With those carbohydrates which are degraded by heat, the basal medium was sterilized by autoclaving, cooled, and $50 \mathrm{ml}$. of a $10 \%$ Seitz-filtered carbohydrate solution added with sterile precautions. The sterility was checked by incubation for 3 days at $37^{\circ}$.

The following carbohydrates were employed: D-mannose, D-xylose, Larabinose, L-rhamnose, D-melibiose, lactose, melezitose, sorbitol, mannitol, salicin and raffinose. 'The first three were sterilized by Seitz-filtration.

Tests were inoculated with 1 drop, incubated for 14 days and observed at $48 \mathrm{hr}$. intervals for colour change from purple to brilliant yellow with accompanying turbidity.

Growth at $15^{\circ}$ and $45^{\circ}$. This was tested in $5 \times \frac{1}{2}$ in. tubes of TJ broth and observed after incubation in an accurately controlled water-bath for 7 days. The inoculum was 1 to 2 drops; all strains were tested in duplicate at both temperatures.

Tolerance of inhibitory substances. TJ broth was used as the basal medium; 
all tests were conducted in bijou bottles and sterilized by autoclaving at $10 \mathrm{lb}$. for $20 \mathrm{~min}$. The following substances were used: $10 \%$ sodium taurocholate, 0.3 and $0.4 \%$ phenol, 4 and $8 \%$ sodium chloride. The inoculum was 1 drop. Tests were incubated for 6 days and tolerance recorded by the presence or absence of turbidity, indicating growth.

Titratable acid production from glucose. Medium: peptone, 0.5\% (w/v); yeast extract, $0.3 \%(\mathrm{w} / \mathrm{v})$; glucose, $0.5 \%(\mathrm{w} / \mathrm{v})$; Tween $80,0.1 \%(\mathrm{v} / \mathrm{v})$; Salts $\mathrm{B}, \mathbf{0 . 5} \%(\mathrm{v} / \mathrm{v})$; at $\mathrm{pH} \mathbf{7 \cdot 2}$, accurately dispensed in $10 \mathrm{ml}$. quantities and sterilized by steaming for $20 \mathrm{~min}$. on 3 consecutive days. The inoculum was 2 to 3 drops; tests were incubated for 3 days and titratable acid was recorded in terms of $0 \cdot 1 \mathrm{~N}$-sodium hydroxide required to neutralize to phenolphthalein. All strains were tested in duplicate and the corrected mean value recorded.

Colony form. Recorded for discrete, $48 \mathrm{hr}$. colonies on the surface of 'TJ agar. Cell form. Recorded from observations made upon heat-fixed, Gram-stained films and unstained hanging-drop preparations of active $24 \mathrm{hr}$. TJ broth cultures. The results obtained by more refined methods are described elsewhere (Davis et al. 1955).

\section{RESULTS}

The 473 strains examined were classified into five species on the basis of the tests described (Table 1). The system embodies groupings in accordance with published definitions which appear to have the greatest validity in the light of the present findings; although the taxonomic rank allotted to them is not necessarily that used by previous workers. The results are in closest agreement with those of Rogosa et al. (1953), and their relationship with those of other workers is explained in the discussion.

\section{Group 1. Lactobacillus acidophilus}

(Comparable to Orla-Jensen's 1919 genus Thermobacterium.) 57 strains were of this type.

Species definition. No gas produced from glucose. Colony small, flat, rough or 'Medusa-head'. Cell form : always fairly long bacilli. No ammonia produced from arginine; grow at $45^{\circ}$ but not at $15^{\circ}$.

Three varieties were encountered in strains of this group.

(a) Variety acidophilus (comparable to the Lactobacillus acidophilus of Wheater $1955 a$ and Rogosa et al. 1953). 47 strains.

Cell form rather variable, moderate to long bacilli, frequently in rigid chains or filaments. Hydrolyses aesculin and sometimes forms acetoin; hippurate not usually hydrolysed. Ferments salicin, lactose, melibiose and mannose, and usually raffinose. Tolerates $10 \%$ bile only poorly; $0.4 \%$ phenol and $4 \%$ but not $8 \%$ sodium chloride tolerated. Acid from glucose $4-6 \mathrm{ml}$.

(b) Variety bulgaricus (comparable to the Lactobacillus bulgaricus of Wheater 1955a). 7 strains.

Bacilli long, rigid, adhering in pairs, fours and short chains. Aesculin and acetoin negative, and hippurate usually negative. Usually ferments lactose 
and sometimes mannose. Tolerates $0.3 \%$ phenol but not $10 \%$ bile, $0.4 \%$ phenol, or 4\% sodium chloride. Acid from glucose 1-2 ml.

(c) Variety lactis (comparable to the Lactobacillus lactis of Sharpe 1955). 3 strains.

Cell form as for variety bulgaricus. Aesculin, hippurate and acetoin negative. Ferments salicin, lactose and mannose. Tolerates $0.3 \%$, but not $0.4 \%$ phenol; does not tolerate $10 \%$ bile or $4 \%$ sodium chloride. Acid from glucose, 1-2 ml.

\section{Group 2. Lactobacillus casei}

(Included in Orla-Jensen's genus Streptobacterium.) 215 strains.

Species definition: no gas produced from glucose. Colony form normally large, smooth, 'mucoid' (Hadley, 1937), convex, entire. Sometimes slightly irregular and occasionally forms large, raised 'Medusa-head' colonies. Young colonies usually rough or semi-rough. Cell form: curling chains of short to medium length bacilli; bacilli tend to curve. No ammonia produced from arginine. Hippurate and aesculin always hydrolyzed. Acetoin usually formed. Grows at $15^{\circ}$, but poorly or not at all at $45^{\circ}$. Ferments mannitol, salicin, and mannose, and often sorbitol, rhamnose, lactose, melibiose and melezitose. Tolerates $0.3 \%$ phenol and $4 \% \mathrm{NaCl}$, and certain strains always tolerate $8 \%$ $\mathrm{NaCl}$ (var. A below); $10 \%$ bile and $\mathbf{0 . 4} \%$ phenol tolerated by most strains. Acid from glucose 4-6 ml.

Five varieties are defined on the basis of fermentation patterns (Table A):

Table A. Varieties of Lactobacillus casei

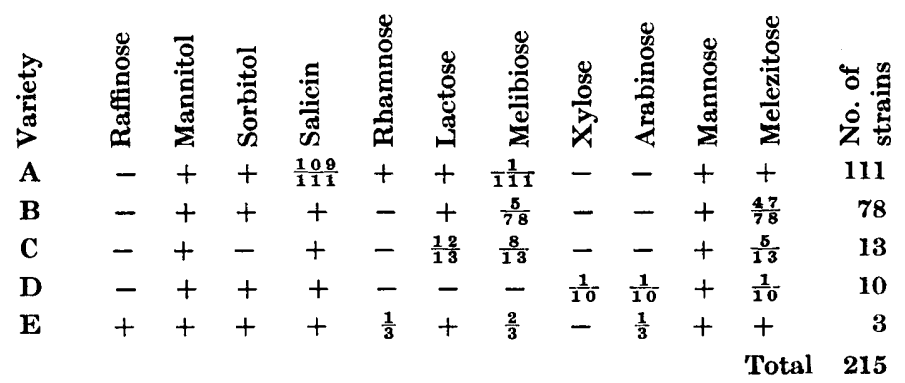

Fractional figures indicate: $\frac{\text { no. of strains positive. }}{\text { no. tested }}$

Group 3. Lactobacillus plantarum

(Included in Orla-Jensen's genus Streptobacterium.) 14 strains.

Species definition. No gas produced from glucose. Colony form smooth, convex, entire. Cell form short; single and paired bacilli. No ammonia produced from arginine. Aesculin and hippurate hydrolyzed and acetoin usually formed. Grows at $15^{\circ}$ but poorly or not at all at $45^{\circ}$. Ferments mannitol, sorbitol, salicin, rhamnose, lactose and mannose, often ferments raffinose, xylose, arabinose and melibiose and occasionally melezitose. Tolerates $10 \%$ bile, $0 \cdot 4 \%$ phenol, $4 \% \mathrm{NaCl}$ and usually $8 \% \mathrm{NaCl}$. Acid from glucose $4-6 \mathrm{ml}$. 
Group 4. Lactobacillus fermenti

(Included in Orla-Jensen's genus Betabacterium.) 164 strains.

Species definition. Gas produced from glucose. Colony form smooth or sometimes semi-rough, convex, entire or slightly irregular, fairly large. Cell form short, single and paired, rather square bacilli. Ammonia produced from arginine. Aesculin, hippurate and acetoin normally negative. Grows well at $45^{\circ}$ but poorly or not at all at $15^{\circ}$. Ferments lactose, melibiose and usually raffinose, and sometimes xylose, arabinose and mannose. Tolerates $10 \%$ bile, $0.4 \%$ phenol, $4 \% \mathrm{NaCl}$ but not $8 \% \mathrm{NaCl}$. Acid from glucose $2-4 \mathrm{ml}$.

Five varieties are defined on the basis of fermentation reaction patterns (Table B).

In variety $A, 14$ strains hydrolyzed hippurate weakly, 3 gave positive reactions with aesculin and 16 appeared to form acetoin. Two strains of variety $\mathbf{B}$ hydrolyzed hippurate, and aesculin was hydrolyzed by one strain of variety $D$ and both of variety $E$.

Table B. Varieties of Lactobacillus fermenti

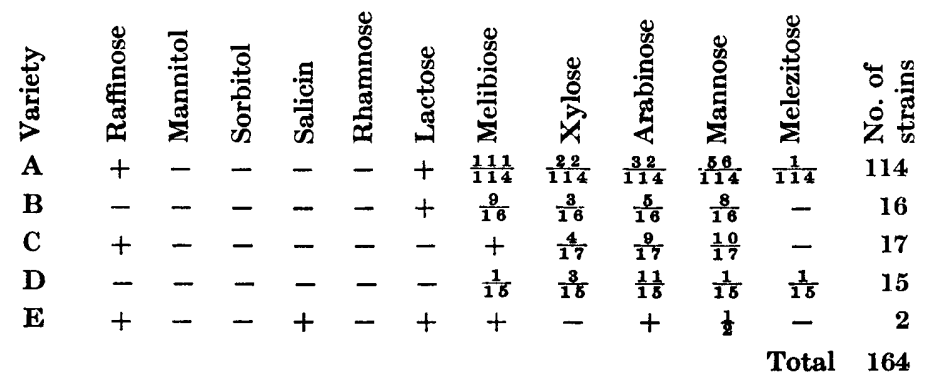

Group 5. Lactobacillus brevis

(Included in Orla-Jensen's genus Betabacterium.) 23 strains.

Species definition. Gas produced from glucose. Colony form small, raised, 'Medusa-head', or rough, or semi-rough. Cell form short to medium length bacilli, in pairs and sometimes short chains. Ammonia not usually produced from arginine. Aesculin and hippurate positive, acetoin negative. Grows at $45^{\circ}$ but not at $15^{\circ}$. Ferments lactose, melibiose and arabinose, and usually raffinose, salicin and xylose. Tolerates $0.4 \%$ phenol and $4 \% \mathrm{NaCl}$, but not $10 \%$ bile or $8 \% \mathrm{NaCl}$. Acid from glucose $1-3 \mathrm{ml}$.

\section{DISCUSSION}

All strains examined fell into one of the two major divisions of the genus, homofermentative and heterofermentative, and were readily distinguishable by the production of gas from glucose in the latter case alone. The homofermentative division is further divisible upon the basis of growth at temperatures of $15^{\circ}$ and $45^{\circ}$ into two groups, whereas the heterofermentative division 
is relatively homogeneous in this respect. The three groups thus obtained correspond exactly to the three genera Thermobacterium, Streptobacterium and Betabacterium into which Orla-Jensen (1919) proposed to divide the lactobacilli. It was considered, however, on the basis of the present findings, that the last two should each be divided into two, and that the resulting five groups were then of equal taxonomic rank, and were of the order of species of Lactobacillus. The further subdivision of some of these groups into a larger number of smaller species is not considered to be taxonomically desirable and these have been relegated to the rank of varieties. An infinity of subdivisions may be made in any biological group, if each least variant character is taken into consideration, and this is especially true of Lactobacillus.

The present classification has been based upon the results of the physiological tests described, and their comparison with those of other workers. It is considered that the high degree of correlation between these, and the morphological characters of the organisms, provides a remarkable confirmation of the validity of the system (Davis et al. 1955).

Many of the tests used were originally devised for the classification of the closely related streptococci. Aesculin hydrolysis (Orla-Jensen, 1934), hippurate hydrolysis (Ayers \& Rupp, 1922), and ammonia production from arginine (Niven, Smiley \& Sherman, 1942) are good examples. Refinement of technique improves the value of these tests, e.g. the hydrolysis of aesculin in the present form provides an excellent diagnostic test, whereas the method used by Rogosa et al. (1953) often produced 'delayed and equivocal' results, and neither these workers nor Wheater $(1955 a)$ obtained the clear distinctions recorded in this case.

Although Rahe (1918) reported the common occurrence of the gas-producing Bacillus acidophil-aerogenes in human saliva, subsequent studies on oral lactobacilli usually omitted any reference to this important character, and its validity was even denied (Whyte, 1942; Stralfors, 1950), until the recent report by Tilden \& Svec (1952). Comparison of the gas detection methods of Gibson \& Abd-el-Malek (1945), Tilden \& Svec (1952) and the Durham tube method of this study, showed that all three gave exactly the same results; but the latter was adopted because of its greater simplicity both in preparation and use.

It was frequently found that supposed variant colonies, selected during the course of purification, were eventually discovered to be exactly like the parent cultures. In some cases the variations were of the type reported by Rogosa et al. (1953), but more commonly they were merely due to the fact that culturally young and crowded colonies of certain species differed in form from older, discrete colonies. This is a point of some importance in consideration of the reliability of colony characteristics as a taxonomic criterion. The colony forms recorded above as the normal type for each group agree with the findings of Rogosa $\mathrm{et} \mathrm{al.} \mathrm{(1953)} \mathrm{and} \mathrm{help} \mathrm{to} \mathrm{clarify} \mathrm{the} \mathrm{earlier} \mathrm{reports} \mathrm{of} \mathrm{Rahe} \mathrm{(1914),}$ Rettger \& Horton (1914), Morishita (1929) and Hadley, Bunting \& Delves (1930), among many others who described this feature.

The relationship between Lactobacillus acidophilus and $\boldsymbol{L}$. bulgaricus has 
long been acknowledged. Their present designation as varieties of one species is considered logical in view of their very close resemblance, as also is the inclusion of the L. lactis strains of Sharpe (1955). Other so-called species, e.g. L. helveticus (Bergey's Manual, 1948) are probably also varieties of this group. Members of the variety acidophilus of $\boldsymbol{L}$. acidophilus are the only strains of any species which appear to be restricted to a parasitic habitat, in this case, the mouth.

It is clear that the Lactobacillus helveticus of Wheater (1955b) is not the same as that described in Bergey's Manual. The former represents the $L$. case $i$ var. rhamnosus of Rogosa etal. (1953) and the L. casei var. A of the present study, while the Bergey species is clearly a member of the high-temperature group, or Thermobacterium of Orla-Jensen (1919) and the L. acidophilus of the present study. The characters quoted by Rogosa et al. (1953, Table 1) agree with the second of the above groupings. It is therefore apparent that the name helveticus has been accorded to quite different organisms, presumably on a basis of origin (from Swiss cheese), exactly as many authorities have tended to identify any lactobacillus from the mouth as $L$. acidophilus. The converse of this fallacious systematic method is found when essentially similar organisms from different sites are accorded different names. The history of classification of lactobacilli abounds with examples of both.

It is true that the members of the genus Lactobacillus are divisible into both major and minor groups, distinguished by characters of greater or less relative importance. This was recognized by Orla-Jensen (1919) when he defined his three genera with their constituent species. But since the compression by Winslow et al. (1920), of Orla-Jensen's three genera into one, Lactobacillus, the tendency has been to define any distinguishable groups as species, with little regard for the significance of the characters employed. Thus the species concept has been of very unequal status in different systems of classification. Rogosa et al. (1953), whose classification system is very like that described here, but more complex in structure and application, showed that nutritional requirements and lactic acid isomer production were in excellent accordance with the morphological and physiological characters employed here.

Some confirmation is also obtainable from the serological groupings of Sharpe (1955), which confirm the close relationship between Lactobacillus casei and the $L$. helveticus of Wheater $(\mathbf{1 9 5 5} b)$, and reflect certain other similarities between group 1 and group 5 , which are apparent in the above definitions. The correlation between these various findings suggests that the relatively simple methods used in this study and by Wheater $(1955 a, b)$ are adequate for the purpose of classification in this genus.

Although noticeably more heterogeneous in physiological reactions than the homofermentative strains, the heterofermentative lactobacilli are nevertheless classifiable into two clear types. The Lactobacillus buchneri of Rogosa et al. (1953) was not identified as a separate species, but certain strains showing some characters intermediate between those of $L$. fermenti and $L$. brevis, e.g. hippurate hydrolysis, weak aesculin hydrolysis, which may represent this species, were encountered (L.fermenti var. E.). The lack of ammonia 
production from arginine by 19 of the 23 L. brevis strains examined is of considerable interest. Briggs (1953) recorded 11 arginine-negative heterofermentative strains in her group VII, and this character is so common as to be almost diagnostic for homofermentative strains.

The new species, Lactobacillus cellobiosus and $L$. salivarius named by Rogosa et al. (1953) from oral sites were not encountered in the present group of oral isolates.

I wish to thank Dr K. A. Bisset for his advice and encouragement throughout this work.

\section{REFERENCES}

Ayers, S. H. \& Rupp, P. (1922). Differentiation of hemolytic streptococci from human and bovine sources by the hydrolysis of sodium hippurate. $J$. infect. Dis. 30, 388.

BarritT, M. M. (1936). The intensification of the Voges-Proskauer reaction by the addition of $\alpha$-naphthol. J. Path. Bact. 42, 441.

Bergey's Manual of Determinative Bacteriology (1948) 6th ed. Edited by Breed, R. S., Murray, E. G. D. \& Hitchens, A. P. London: Baillière, Tindall and Cox.

Briggs, M. (1953). The classification of lactobacilli by means of physiological tests. J. gen. Microbiol. 9, 234.

Briggs, M. \& Briggs, C. A. E. (1954). The lactobacilli : a review of the literature with special reference to taxonomy. Dairy Sci. Abstr. 16, 252.

Davis, G. H. G., Bisser, K. A. \& Hale, C. M. F. (1955). Correlation between morphological and physiological characters in the classification of members of the genus Lactobacillus. J. gen. Microbiol. 13, 68.

Gibson, T. \& ABD-EL-Malek, Y. (1945). The formation of $\mathrm{CO}_{2}$ by lactic acid bacteria and Bacillus licheniformis and a cultural method of detecting the process. J. Dairy Res. 14, 35.

Grubb, R. \& Krasse, B. (1953). Classification of oral strains of lactobacilli. Acta path. microbiol. scand. 32, 539.

HADLEY, P. (1937). Further advances in the study of microbic dissociation. J. infect. Dis. 60, 129.

Haduey, F., Bunting, R. W. \& Delves, E. A. (1930). Recognition of Bacillus acidophilus associated with dental caries: A preliminary report. J. Amer. dent. Ass. 17, 2041.

KuLP, W. L. (1927). An agar medium for plating L. acidophilus and L. bulgaricus. Science, 66, 512.

Mackie, T. J. \& McCartney, J. E. (1950). Handbook of Practical Bacteriology, 8th ed. Edinburgh: E. and S. Livingstone Ltd.

Morishita, T. (1929). Studies on dental caries, with special reference to aciduric organisms associated with this process. I. Isolation and description of organisms. J. Bact. 18, 181.

Niven, Jun., C. F., Smiley, K. L. \& Sherman, J. M. (1942). The hydrolysis of arginine by streptococci. $J$. Bact. 43, 651 .

Orla-Jensen, A. D. (1934). About the application of aesculin for the identification of bacteria. Acta path. microbiol. scand. 11, 312.

Orla-Jensen, S. (1919). The Lactic Acid Bacteria. Copenhagen: Andr. Fred. Host \& Son.

Peters, V. J. \& Snell, E. E. (1954). Peptides and bacterial growth. VI. The nutritional requirements of Lactobacillus delbrueckii. J. Bact. 67, 69.

RAHE, A. H. (1914). An investigation into the fermentative activities of aciduric bacteria. J. infect. Dis. 15, 141. 
RAHE, A. H. (1918). The classification of the aciduric bacteria. J. Bact. 3, 407.

Rettger, L. F. \& Horton, G. D. (1914). A comparative study of the intestinal flora of white rats kept on experimental and ordinary mixed diets. Z Zbl. Bakt (Abt. 1), 73, 362.

Rogosa, M., Mitchell, J. A. \& Wiseman, R. F. (1951). A selective medium for the isolation and enumeration of oral lactobacilli. J. dent. Res. 30, 682.

Rogosa, M., Wiseman, R. F., Mitchell, J. A., Disraely, M. N. \& Beaman, A. J. (1953). Species differentiation of oral lactobacilli from man including descriptions of Lactobacillus salivarius nov. spec. and Lactobacillus cellobiosus nov. spec. J. Bact. 65, 681.

Sharpe, M. E. (1955). A serological classification of lactobacilli. J. gen. Microbiol. $12,107$.

Stralfors, A. (1950). Investigations into the bacterial chemistry of dental plaques. Odont. Tidskr. 58, 155.

Sullivan, H. R. (1939). The viability and maintenance of oral strains of Lactobacillus acidophilus. J. Path. Bact. 48, 607.

Tilden, E. B. \& Svec, M. (1952). Further studies of a differential culture technique for estimations of acidogenic bacteria in saliva. II. Species of lactobacilli isolated from saliva and their distribution in a group of children. J. dent. Res. 31, 831.

Topley \& Wilson's Principles of Bacteriology and Immunity (1946). 3rd ed. Edited by Wilson, G. S. \& Miles, A. A. London: Edward Arnold.

WhEATER, D. M. $(1955 a)$. The characteristics of Lactobacillus acidophilus and Lactobacillus bulgaricus. J. gen. Microbiol. 12, 123.

WheATER, D. M. (1955 b). The characteristics of Lactobacillus plantarum, L. helveticus and $L$. casei. J. gen. Microbiol. 12, 133.

Whyte, R. (1942). A study of oral aciduric micro-organisms. Brit. dent. J. 74, 309.

Winslow, C.-E. A., Broadhurst, J., Buchanan, R. E., Krumwiede, C., Rogers, L. A. \& Smith, G. H. (1920). The families and genera of the bacteria. J. Bact. 5, 191. 